\title{
Correspondence
}

\section{DEAR EDITOR}

P. C. Wickens' addition to note 66.9 by H. M. Finucan reminded me of the famous problem 'is it possible to construct a rectangular block such that the length of each edge, facial diagonal and spacial diagonal is an integer?'

Brute force has produced a number of partial solutions, for instance

$$
\begin{aligned}
& 5^{2} .29 \cdot 101=73225=240^{2}+117^{2}+44^{2}=240^{2}+125^{2}=117^{2}+244^{2} \\
& \quad=44^{2}+267^{2}
\end{aligned}
$$

and

$$
\begin{aligned}
& 13.37 .409=196729=275^{2}+252^{2}+240^{2}=275^{2}+348^{2}=252^{2}+365^{2} \\
& =240^{2}+373^{2}
\end{aligned}
$$

which hold for the surface but not the main diagonal.

Have any members found other solutions to, or methods of approaching, this connundrum?

Yours sincerely, PETER MASON

St. Albans School, Abbey Gateway, St. Albans, Herts

\section{Reviews}

Core books in advanced mathematics, by C. T. Moss, C. Plumpton, T. Bridgeman, P. C. Chatwin, H. M. Kenwood. $£ 1.65$ each. 1983

Differentiation, Vectors, Integration, Curve sketching. Pp 56, 64, 76, 55. ISBN 0-33331794-7, 31791-2, 31793-9, 34803-6 (Macmillan Education)

The aim of each book is "to develop a major topic of the single-subject syllabuses giving essential book work and worked examples arising from the authors' vast experience of examining at this level and including past GCE questions also". These four are the start of a series. When complete, the whole set is intended to give comprehensive syllabus coverage of single-subject A-level Mathematics.

In general the content of each book is predictable: little pretension is made to novelty of treatment or presentation. The usefulness of the series is presumably the convenient packaging of the syllabus into single topic booklets. The authors suggest that institutions or students could buy them to cover topics not included in books already owned, or as a course of supplementary examples and exercises.

The primary emphasis is on technique. The books are intended for consumers of mathematics, not specialist mathematicians. Supplying justifications, still less proofs, is not seen as important. The accent is on stating the significant results. Nevertheless, these often receive quite careful treatment. I found the following in Section 3.8 of the booklet on differentiation:

"A maximum is the value of the function at a point where $f^{\prime}(x)=0$ and $f^{\prime}(x)$ changes from positive to negative for values of $x$ just less and just greater respectively than that for which $f^{\prime}(x)=0$, i.e. as $x$ goes through the point." 